\title{
Ultrasonic Shear Device versus Monopolar Electric Cautery in Conservative Breast Surgery Following Neoadjuvant Chemotherapy: A Comparative Study
}

Islam Khaled ( $\nabla$ dr.islam.ahmed@med.suez.edu.eg )

Suez Canal University Faculty of Medicine https://orcid.org/0000-0001-6577-4312

Ihab Saad

National Cancer Institute Cairo University

Hany Soliman

Cairo University Kasr Alainy Faculty of Medicine

Mohammed Faisal

Suez Canal University Faculty of Medicine

\section{Research}

Keywords: Breast Cancer, Conservative Surgery, Neoadjuvant Chemotherapy, Harmonic Scalpel

Posted Date: April 19th, 2021

DOI: https://doi.org/10.21203/rs.3.rs-409844/v1

License: (c) (i) This work is licensed under a Creative Commons Attribution 4.0 International License.

Read Full License 


\section{Abstract}

Background: Surgical devices are commonly used during breast-conservative surgery (BCS) to provide better hemostasis. Ultrasonic shear has recently gained momentum as an effective tool for intraoperative bleeding reduction. This comparative study was designed to determine the efficacy of Harmonic focus in reducing postoperative complications of BCS following neoadjuvant chemotherapy (CTH), in comparison to the conventional method using monopolar diathermy.

Methods: We conducted a prospective, non-randomized, comparative, study on patients scheduled to undergo BCS with axillary dissection or sentinel lymph node biopsy after neoadjuvant CTH. Patients were recruited consecutively throughout the study period and were divided in an equal manner to undergo either monopolar electrocautery or Harmonic focus ${ }^{\circledR}$.

Results: Patients in the Harmonic Focus group had significantly shorter operative time than the monopolar electrocautery group (101.32 \pm 27.3 versus $139.3 \pm 31.9$ minutes, respectively; $p<0.001)$. Besides, the blood loss was significantly lower in the Harmonic Focus group (117.14 \pm 35.6 versus $187 \pm$ $49.8 \mathrm{~mL}$, respectively; $\mathrm{p}<0.001$ ). Postoperatively, patients in the Harmonic Focus group had a significantly lower volume of chest wall drain $(p<0.001)$ and shorter rime till drain removal $(p<0.001)$. Likewise, patients in the Harmonic Focus group had a significantly lower volume of axillary drain and shorter rime till drain removal than monopolar electrocautery $(p<0.001)$. The incidence of postoperative complications was comparable between both groups $(p=0.128)$.

Conclusions: In conclusion, the current study confirms the superiority of Harmonic Focus, compared to monopolar electrocautery, amongst patients receiving neoadjuvant CTH before BCS.

\section{Background:}

Breast cancer (BC) is the most prevalent cancer type in women and takes pole position in cancer-related deaths as well(1). The latest release of the GLOBOCAN statistics in 2018 revealed that BC comprises $11.6 \%$ of total cancer cases and $6.6 \%$ of all cancer-related mortality(2). Prevalence rates in the Middle East are comparatively higher; where $\mathrm{BC}$ is involved in $27.7 \%$ to $38.2 \%$ of all reported tumors in the region(3). In Egypt, BC is again the apex of all cancers in women; causing $32.04 \%$ of cases(4) and $15 \%$ of deaths(5). Locally-advanced BC is a diverse group of tumors that encompasses inoperable or operable tumors without the presence of distant metastasis(6). Over the past few decades, breast conservative surgery (BCS) has emerged as a promising technique for patients wishing to preserve their breast, with comparable survival rates to conventional mastectomy(7); it is usually accompanied by axillary lymph node dissection owing to the high possibility of metastasis and the prognostic importance of histological examination of axillary lymph nodes(8).

Recent literature demonstrated that the use of BCS has increased in the setting of locally-advanced BC to reach up to $80 \%$ in some cohorts, especially after the use of neoadjuvant chemotherapy (CTH). Although it was originally proposed for inoperable, locally-advanced, BC, the use of neoadjuvant CTH in the setting 
of earlier, operable, cases has been recently popularized by many centers(9). Neoadjuvant CTH has the potential of converting inoperable to operable cases, reducing tumor size before surgery, and evaluation of treatment response(10). While initial trials showed no survival benefits of neoadjuvant regimen over adjuvant $\mathrm{CTH}$, the emergence of taxanes, and other novel agents, has dramatically improved the pathological response following neoadjuvant CTH and, hence, improved the clinical outcomes of the patients(11).

Despite being generally safe, BCS is not a complication-free procedure; the surgery can be complicated by postoperative wound infection, seroma, dehiscence, bleeding, as well as thromboembolic events(12). The utilization of neoadjuvant CTH can potentially increase the risk of postoperative complications, especially infection, owing to its associated neutropenia(13). Nonetheless, the impact of neoadjuvant chemotherapy on the postoperative complications of BCS is still controversial.

Surgical devices are commonly used during BCS to provide better hemostasis of small blood vessels, hence reducing the risk of bleeding and prolonged operation(14). Conventional electrocautery is a widely available, easy-to-use, and cheap method for blood vessel sealing during the surgery; however, the tool is limited by the induction of postoperative inflammatory reaction and wide burn area, which can increase the risk of postoperative seroma; besides, the excessive smoking from electrocautery may compromise the surgical field(15).

In a recent systematic review, electrocautery was associated with the highest incidence of postoperative seroma among surgical devices for BCS(16). Ultrasonic shear has recently gained momentum, mainly in the setting of laparoscopic surgery, as an effective tool for intraoperative bleeding reduction(17). In patients scheduled for BC surgery, the Ultrasonic shear has been investigated for reducing the incidence of postoperative seroma with equivocal results $(18,19)$. This comparative study was designed to determine the efficacy of Harmonic focus in reducing postoperative complications of BCS following neoadjuvant $\mathrm{CTH}$, in comparison to the conventional method using monopolar diathermy.

\section{Methods:}

Prior to the study's initiation and first patient enrollment, official approvals of the responsible ethics committee were gained (IRB No. 3128 and 124 respectively).

\section{Study Design and Population:}

We conducted a prospective, non-randomized, comparative through the period from January 2018 to December 2020: Adults (aged > 18 years old) who were scheduled to undergo BCS with axillary dissection or sentinel lymph node biopsy after neoadjuvant CTH were included. We excluded cases with a history of disease recurrence, radiation therapy, and those who refuse to sign the informed consent. Patients were recruited consecutively throughout the study period and were divided in an equal manner to undergo either monopolar electrocautery or Harmonic focus ${ }^{\circledR}$. 


\section{Sample Size Calculation:}

The sample size calculation is based on Bohm et al study. With the difference in proportions of overall seroma ( $20.4 \%$ vs. $5.8 \%$ ), a predetermined $80 \%$ power of the study, and $95 \%$ level of confidence, the sample size was calculated to be 86 patients (43 patients for each technique) using the G*Power version 3.1.9.2.

\section{Preoperative Data Collection and Surgical Techniques:}

Data regarding demographic characteristics, body mass index (BMI), history of chronic disease, histopathological type of tumor, hormonal status, tumor size, tumor stage, neoadjuvant chemotherapy regimen, and radiological response were collected from all patients. All the patients enrolled in the study had metastatic workup in the form of a CT chest, abdomen, and pelvis with a bone scan when indicated; patients with metastatic disease were excluded from the study. With immunohistochemistry done for all patients, all patients received chemotherapy (AC for four cycles) followed by (Taxol four cycles) and Herceptin added to the patients with Her2neu overexpression. Clinical and radiological assessment of the response done every four cycles. The radiological response to neoadjuvant chemotherapy was assessed according to the Response Evaluation Criteria in Solid Tumors (RECIST v1.1).

All patients underwent the BCS according to the institution's standard protocols after NCTH. In the monopolar diathermy group, we utilized ErbeVio $300 \mathrm{D}$ to dissect the skin flap, with wide local excision with a safety margin and, axillary dissection as indicated. In the Harmonic group, the Harmonic Focus was utilized for the wide local excision along with axillary dissection. The blood and lymphatic vessels were sealed using Harmonic Focus, without any attempts to use cautery or clips. In patients who underwent BCS, after identification of nerve supply, the Harmonic Focus was used to ligate veins and arterial supply of the resected segment of the breast, as well as dissection of axially lymph nodes and the surrounding blood vessels (Fig.1). Finally, two 16-F vacuum drains were allocated in the chest wall and axilla. The intraoperative blood loss was measured by calculating the weight of used sponges, with each gram corresponds to $\mathrm{mL}$ of blood loss.

Broad-spectrum antibiotics were prescribed for 12 hours after the operation. Postoperative pain was recorded until the end of the $7^{\text {th }}$ postoperative day using a visual analog scale (VAS). The assessment of the surgical site for infection or necrosis was done until the patients' discharge. Patients were discharged with drains and were instructed to measure the daily amount of drain volume. The drains were removed within an average of five days after the operation. The patients were followed up on weekly basis for four weeks to assess the development of seroma.

\section{Study's Endpoints:}

The primary endpoint of the present study was the incidence of postoperative seroma and the means seroma cumulative volume 30 days after the surgery. The seroma was diagnosed by ultrasound (US) or subcutaneous aspiration-proven serious fluid beneath the skin flaps to the extent that causes the patient's 
discomfort within one month after the operation. The secondary endpoints included intraoperative blood loss, operative time, amount of chest wall and axillary drain, days till chest wall and axillary drain removal, hospital stay, postoperative pain, and incidence of postoperative complications.

\section{Statistical analysis:}

The statistical data analysis was done using Microsoft ${ }^{\circledR}$ Excel® 2013 (15.0.4420.1017) 32-bit software. The mean ( \pm standard deviation $[S D]$ ) and frequencies were used to summarized continuous and categorical data, respectively. The hypothesize of the association between qualitative data was tested using Chi-square or Fisher's exact tests; while hypothesizing of the association between quantitative data was performed using Mann-Whitney tests. A p-value of less than $5 \%$ was used to reject the null hypothesize.

\section{Results:}

A total of 100 patients were divided into a 1:1 ratio to undergo Harmonic Focus or monopolar electrocautery. One patient in the Harmonic Focus was lost during the follow-up period, thus a total of 99 patients were included in the final dataset analysis. The mean age in the monopolar electrocautery and the Harmonic Focus groups was $49.51 \pm 11.3$ and $48.1 \pm 11.1$ years old, respectively $(p=0.53)$. There were no statistically significant differences between studied groups in terms of $\operatorname{sex}(p=0.51), B M I(p$ $=0.51)$, smoking $(p=0.78)$, family history of $B C(p=0.96)$, history of other chronic diseases, histological types ( $p=0.32)$, receptor status, tumor size, TNM stage ( $p=0.15)$, chemotherapy regimens, and radiological response $(p=0.72$; Table 1$)$.

In terms of intraoperative characteristics, patients in the Harmonic Focus group had significantly shorter operative time than the monopolar electrocautery group (101.32 \pm 27.3 versus $139.3 \pm 31.9$ minutes, respectively; $p<0.001)$. Besides, the blood loss was significantly lower in the Harmonic Focus group (117.14 \pm 35.6 versus $187 \pm 49.8 \mathrm{~mL}$, respectively; $p<0.001)$. No significant differences were detected in other intraoperative characteristics (Table 2).

Postoperatively, patients in the Harmonic Focus group had a significantly lower volume of chest wall drain (86.83 \pm 20.7 versus $147.5 \pm 35.4$ in monopolar electrocautery; $\mathrm{p}<0.001$ ) and shorter rime till drain removal ( $2.551 \pm 0.67$ versus $4.12 \pm 0.96$ in monopolar electrocautery; $p<0.001)$. Likewise, patients in the Harmonic Focus group had a significantly lower volume of axillary drain and shorter rime till drain removal than monopolar electrocautery $(p<0.001)$. The frequency of pain was lower in the Harmonic Focus group 72 hours after the procedure $(4.1 \%$ versus $28 \% ; p=0.007)$. The incidence of postoperative complications was comparable between both groups $(p=0.128)$. The incidence of postoperative complications was comparable between both groups $(p=0.128)$. Two patients developed postoperative seroma in the Harmonic Focus group and three patients in the monopolar electrocautery group $(p=0.63$;

Table 3). 
The association analysis showed that patients with seroma were more likely to have Her2-positive status ( $80 \%$ versus $36.1 \%$ in no seroma group; $p=0.001$ ), advanced TNM stages $(p=0.018)$, and shorter days to chest drain removal ( $2.551 \pm 0.67$ versus $4.12 \pm 0.96$ days in no seroma group; $p=0.046)$. On the other hand, we found that there were no significant differences between patients with and without seroma regarding the type of neoadjuvant chemotherapy $(p=0.42)$, the number of cycles $(p=0.49)$, radiological response $(p=0.43)$, pre and post-chemotherapy tumor sizes, intraoperative blood loss $(p=0.25)$, operative time $(p=0.21)$, and postoperative characteristics $(p>0.05$; Table 4$)$.

The regression analysis showed that Her-2 positive status was an independent predictor of seroma development $(\mathrm{OR}=11.72,95 \% \mathrm{Cl}[1.1-128.6], \mathrm{p}=0.046$; Table 5).

\section{Discussion:}

Neoadjuvant CTH has emerged as an effective modality in the setting of BCS, which has the advantages of downstaging tumor size before surgery and assessing treatment response. In return, neoadjuvant CTH can permit less-invasive surgery, better cosmetic outcomes, and fewer risks of postoperative lymphedema. An additional advantage of neoadjuvant CTH is its ability to aid intraoperative tumor recognition and reduce the possibility of extensive residual disease(10). On the other hand, the utilization of neoadjuvant CTH can potentially increase the risk of certain postoperative complications, especially infection, owing to its associated neutropenia(13); nonetheless, the impact of neoadjuvant CTH on postoperative complications of BCS is still controversial. Despite that the Ultrasonic shear is a wellestablished tool in various surgery, there is a controversy regarding its superiority over conventional methods in the setting of BCS. Moreover, no previous study has examined the superiority of Ultrasonic shear in patients receiving neoadjuvant CTH. In the present comparative study, we found that the use of the Harmonic Focus scalpel was associated with shorter operative time and less blood loss than conventional electrocautery. Moreover, patients in the Harmonic Focus group had a significantly lower volume of drain and shorter time till drain removal, compared to the monopolar electrocautery group; as well as less pain at the $3^{\text {rd }}$ postoperative day. On the other hand, patients in the Harmonic Focus scalpel group had comparable rates of postoperative complications to patients in the monopolar electrocautery group.

Proper hemostatic control is critical intraoperatively to reduce blood loss, time of surgery, and, subsequently, postoperative morbidity and operative expenses. As mentioned before, conventional electrocautery is limited by excessive time for tissue dissection and wide thermal damage; which, in return, can result in excessive blood loss and prolonged operative time(20). The Ultrasonic shear works by dividing the tissues longitudinally through high-frequency ultrasonic waves, which takes potentially less time for tissue damage than conventional methods. Besides, the Ultrasonic shear produces a lower temperature than electrocautery, hence, less liability to excessive tissue damage and blood loss. Finally, the coagulating shears lead to the development of coagulum that effectively seals blood vessels(21). In the present comparative study, we demonstrated that the Ultrasonic shear had the advantage of less operative time and blood loss, compared to monopolar electrocautery, in the setting of BCS with 
lymphadenectomy. Our findings are in line with recent systematic reviews indicating less amount of blood loss following Harmonic scalpel, compared to conventional methods(22,23); however, it should be noted that no previous studies are assessing Ultrasonic shear in the setting of neoadjuvant CTH.

Previous reports demonstrated that drainage volume and duration till drain removal are positively correlated with the risk of local infectious complications(24). In the present study, we demonstrated that the Ultrasonic shear led to lower drainage volume and shorter rime till drain removal, compared to monopolar electrocautery. This was in agreement with a 2016 meta-analysis of 12 studies, which demonstrated lower drainage volume following Harmonic scalpel, compared to conventional electrocautery(22). In another two reports from China and Germany, Harmonic Focus significantly reduce the drainage volume and time until drain removal, compared to monopolar electrocautery, among women undergoing BCS(18). These findings are hypothesized to stem from the ability of the Ultrasonic shear to deal with lymphatic vessels with no re-opening again(25).

Postoperative seroma, a term used to describe an accumulation of serious fluid beneath the flap or in the axially dead space, is a common complication following BC surgery, with a reported incidence of 2-80\% according to the nature of the procedures(26). Although seroma is not associated with a significant increase in mortality, it can trouble the postoperative course of the affected patients by increasing the risk of prolonged draining, infection, and reoperation, which, in return, can significantly delay adjuvant chemotherapy(26). Surgical techniques and devices are thought to significantly impact the risk of postoperative seroma. For example, electrocautery was found to be associated with the highest incidence of postoperative seroma among surgical devices for BC surgery(16). On the other hand, the Ultrasonic shear is thought to reduce the incidence of seroma through minimal tissue damage, proper hemostasis, and lower risk of flap necrosis, compared to other techniques. However, in the present study, we demonstrated that the rate of postoperative seroma was comparable between Ultrasonic shear and monopolar electrocautery. In concordance with our findings, Archana et al.(25), and Selvendran et al.(27), reported no significant difference between Ultrasonic shear and monopolar electrocautery regarding the incidence of post-BC surgery seroma. Similar findings were reported by other studies $(28,29)$. Nonetheless, it should be noted that the current body of evidence shows conflicting results regarding the role of Ultrasonic shear in reducing the incidence of seroma as other reports demonstrated a significant reduction in seroma following Harmonic scalpel, as compared to monopolar electrocautery, in patients undergoing BC surgery $(22,23)$. Such contradictory results can be explained by wide variations in patients' characteristics, type of surgery, surgeon's experience, the definition of seroma, and length of follow-up amongst the published studies. Further, a well-designed trial with multinational collaboration is warranted to investigate the impact of Ultrasonic shear on seroma prevention following BC surgery.

Older age, large tumor size, advanced tumor stage, and history of anticoagulants or tamoxifen are among the common patient-related risk factors for postoperative seroma(30). In our cohort, we found that Her-2 positive status was an independent predictor of seroma development; while patients with seroma were more likely to have advanced TNM stages and shorter days to chest drain removal. Our findings are in 
line with previous reports indicating significant associations between hormonal status and the risk of postoperative seroma.

\section{Conclusions:}

the current study confirms the superiority of Harmonic Focus, compared to monopolar electrocautery, in many intra and postoperative parameters such as operative time, amount of blood loss, drainage volume, and length of drain placement amongst patients receiving neoadjuvant CTH before BCS. On the other hand, the present study found no significant difference between Harmonic Focus and monopolar electrocautery regarding the incidence of postoperative seroma and other complications. Nonetheless, Harmonic Focus is a feasible and safe technique, and it should be favored over conventional techniques in well-equipped centers. Further, a well-designed trial with multinational collaboration is warranted to investigate the impact of Ultrasonic shear on seroma prevention amongst patients receiving neoadjuvant CTH before BCS.

\section{Abbreviations}

\begin{tabular}{|ll|}
\hline BCS & breast-conservative surgery \\
\hline CTH & chemotherapy \\
\hline BC & Breast cancer \\
\hline BMI & body mass index \\
\hline RECIST & Response Evaluation Criteria in Solid Tumo \\
\hline NCTH & Neoadjuvant chemotherapy \\
\hline AC & Adriamycin, Cyclophosphamide \\
\hline TT & Trastuzumab \\
\hline T & Taxol \\
\hline CT & Computed tomography \\
US & Ultrasound \\
\hline OR & Odds ration \\
\hline CR & Clinical response \\
\hline DP & Disease persistent \\
\hline SD & Stationary response \\
PR & Partial response \\
\hline
\end{tabular}




\section{Declarations}

- Ethics approval and consent to participate: Official approvals of the responsible ethics committee were gained from Suez Canal University Hospitals, National Cancer Institute of Egypt and Saudi German Hospital, Jeddah (IRB No. 3128 and 124 respectively).

- Consent for publication: Not applicable

- Availability of data and materials: Not applicable

- Competing interests: The authors declare that they have no competing interests

- Funding: authors declare that they have no funding

- Authors' contributions:

- Study conception and design: IK, IS and HS

- Acquisition of data: IK, HS, MF

- Analysis and interpretation of data: IK, IS and MF

- Drafting of manuscript: IK, IS and HS

- Critical revision of manuscript: IK, IS, HS, MF.

- All authors have read and approved the manuscript.

- Acknowledgment: None

\section{References}

\section{References:}

1. Elezaby M, Lees B, Maturen KE, Barroilhet L, Wisinski KB, Schrager S, et al. BRCA Mutation Carriers: Breast and Ovarian Cancer Screening Guidelines and Imaging Considerations. Radiology. 2019 Jun;291(3):554-69.

2. Bray F, Ferlay J, Soerjomataram I, Siegel RL, Torre LA, Jemal A. Global cancer statistics 2018 : GLOBOCAN estimates of incidence and mortality worldwide for 36 cancers in 185 countries. CA Cancer J Clin [Internet]. 2018 Sep 12 [cited 2018 Oct 11]; Available from: http://doi.wiley.com/10.3322/caac.21492.

3. Laraqui A, Uhrhammer N, El Rhaffouli H, Sekhsokh Y, Lahlou-Amine I, Bajjou T, et al. BRCA genetic screening in middle eastern and North African: Mutational spectrum and founder BRCA1 mutation (c.798-799delTT) in North African. Disease Markers. 2015.

4. Ibrahim AS, Khaled HM, Mikhail NN, Baraka $\mathrm{H}$, Kamel $\mathrm{H}$. Cancer incidence in egypt: results of the national population-based cancer registry program. J Cancer Epidemiol [Internet]. 2014 Sep 21 [cited 2019 Feb 19];2014:437971. Available from: http://www.ncbi.nlm.nih.gov/pubmed/25328522.

5. Faisal M, Fathy H, Shaban H, Abuelela ST, Marie A, Khaled I. A novel technique of harmonic tissue dissection reduces seroma formation after modified radical mastectomy compared to conventional 
electrocautery: A single-blind randomized controlled trial. Patient Saf Surg [Internet]. 2018 May 17 [cited 2020 Oct 13];12(1). Available from: /pmc/articles/PMC5956966/?report = abstract.

6. Costa R, Hansen N, Gradishar WJ. Locally advanced breast cancer. In: The Breast: Comprehensive Management of Benign and Malignant Diseases. Elsevier Inc.; 2018. p. 819-831.e6.

7. Chirappapha P, Kongdan Y, Vassanasiri W, Ratchaworapong K, Sukarayothin T, Supsamutchai C, et al. Oncoplastic technique in breast conservative surgery for locally advanced breast cancer. Gland Surg [Internet]. 2014;3(1):22-27. [cited 2020 Oct 20 ;. Available from: /pmc/articles/PMC4115767/? report $=$ abstract.

8. Muhammad R, Johann KF, Saladina JJ, Harlina MLN, Niza ASS. Ultracision versus electrocautery in performing modified radical mastectomy and axillary lymph node dissection for breast cancer: A prospective randomized control trial. Med J Malaysia. 2013;68(3):204-7.

9. Selli C, Sims AH. Neoadjuvant Therapy for Breast Cancer as a Model for Translational Research [Internet]. Vol. 13, Breast Cancer: Basic and Clinical Research. SAGE Publications Ltd; 2019 [cited 2020 Aug 22]. Available from: /pmc/articles/PMC6381436/?report = abstract.

10. Charfare H, Limongelli S, Purushotham AD. Neoadjuvant chemotherapy in breast cancer [Internet]. Vol. 92, British Journal of Surgery. Br J Surg; 2005 [cited 2020 Aug 22]. p. 14-23. Available from: https://pubmed.ncbi.nlm.nih.gov/15635596/.

11. Masood S. Neoadjuvant chemotherapy in breast cancers [Internet]. Vol. 12, Women's Health. SAGE Publications Ltd; 2016 [cited 2020 Aug 22]. p. 480-91. Available from: /pmc/articles/PMC5373271/?report = abstract.

12. ten Wolde B, Kuiper M, de Wilt JHW, Strobbe LJA. Postoperative Complications After Breast Cancer Surgery are Not Related to Age. Ann Surg Oncol [Internet]. 2017 Jul 1 [cited 2020 Jun 25];24(7):1861-7. Available from: https://link.springer.com/article/10.1245/s10434-016-5726-x.

13. Bear HD, Anderson S, Brown A, Smith R, Mamounas EP, Fisher B, et al. The effect on tumor response of adding sequential preoperative docetaxel to preoperative doxorubicin and cyclophosphamide: Preliminary results from National Surgical Adjuvant Breast and Bowel Project Protocol B-27. J Clin Oncol. 2003;21(22):4165-74.

14. Hashemi E, Kaviani A, Najafi M, Ebrahimi M, Hooshmand H, Montazeri A. Seroma formation after surgery for breast cancer. World J Surg Oncol. 2004;2.

15. Yilmaz KB, Dogan L, Nalbant H, Akinci M, Karaman N, Ozaslan C, et al. Comparing scalpel, electrocautery and ultrasonic dissector effects: The impact on wound complications and proinflammatory cytokine levels in wound fluid from mastectomy patients. J Breast Cancer. 2011;14(1):58-63.

16. Janis JE, Khansa L, Khansa I. Strategies for postoperative seroma prevention: A systematic review. Vol. 138, Plastic and Reconstructive Surgery. 2016. p. 240-52.

17. Bessa SS, Abdel-Razek AH, Sharaan MA, Bassiouni AE, El-Khishen MA, El-Kayal ESA. Laparoscopic cholecystectomy in cirrhotics: A prospective randomized study comparing the conventional 
diathermy and the ultrasonic shear for gallbladder dissection. J Laparoendosc Adv Surg Tech. 2011;21(1):1-5.

18. He Q, Zhuang D, Zheng L, Fan Z, Zhou P, Zhu J, et al. Harmonic focus versus electrocautery in axillary lymph node dissection for breast cancer: A randomized clinical study. Clin Breast Cancer. 2012;12(6):454-8.

19. Manjunath S, Ramesh RS, Goel KS. V. Ultrasonic Shears Versus Electrocautery in Axillary Dissection for Breast Cancer-A Randomized Controlled Trial. Indian J Surg Oncol. 2014;5(2):95-8.

20. Fritz DK, Matthews TW, Chandarana SP, Nakoneshny SC, Dort JC. Ultrasonic shear impact on blood loss and operating time in major head and neck surgery: a randomized clinical trial. J Otolaryngol Head Neck Surg [Internet]. 2016 Nov 8 [cited 2020 Aug 12];45(1):1-6. Available from: /pmc/articles/PMC5100249/?report = abstract.

21. Siperstein AE, Berber E, Morkoyun E. The use of the ultrasonic shear vs conventional knot tying for vessel ligation in thyroid surgery. Arch Surg [Internet]. 2002 Feb 1 [cited 2020 Aug 12];137(2):137-42. Available from: https://jamanetwork.com/journals/jamasurgery/fullarticle/212119.

22. Cheng H, Clymer JW, Ferko NC, Patel L, Soleas IM, Cameron CG, et al. A systematic review and metaanalysis of harmonic technology compared with conventional techniques in mastectomy and breastconserving surgery with lymphadenectomy for breast cancer [Internet]. Vol. 8, Breast Cancer: Targets and Therapy. Dove Medical Press Ltd.; 2016 [cited 2020 Aug 12]. p. 125-40. Available from: /pmc/articles/PMC4958357/?report = abstract.

23. Huang J, Yu Y, Wei C, Qin Q, Mo Q, Yang W. Ultrasonic shear versus electrocautery dissection in modified radical mastectomy for breast cancer: A meta-analysis. PLoS One. 2015;10(11).

24. Porcel JM. Chest Tube Drainage of the Pleural Space: A Concise Review for Pulmonologists [Internet]. Vol. 81, Tuberculosis and Respiratory Diseases. Korean National Tuberculosis Association; 2018 [cited 2020 Aug 12]. p. 106-15. Available from: /pmc/articles/PMC5874139/? report = abstract.

25. Archana A, Sureshkumar S, Vijayakumar C, Palanivel C. Comparing the Ultrasonic shear with Electrocautery in Reducing Postoperative Flap Necrosis and Seroma Formation after Modified Radical Mastectomy in Carcinoma Breast Patients: A Double-Blind Prospective Randomized Control Trail. Cureus [Internet]. 2018 Apr 13 [cited 2020 Aug 12];10(4). Available from: /pmc/articles/PMC5999389/? report = abstract.

26. Srivastava V, Basu S, Shukla VK. Seroma formation after breast cancer surgery: What we have learned in the last two decades [Internet]. Vol. 15, Journal of Breast Cancer. Korean Breast Cancer Society; 2012 [cited 2020 Jun 25]. p. 373-80. Available from: / pmc/articles/PMC3542843/?report = abstract.

27. Selvendran S, Cheluvappa R, Truong VK, Yarrow S, Pang TC, Segara D, et al. Efficacy of harmonic focus scalpel in seroma prevention after axillary clearance. Int J Surg. 2016 Jun 1;30:116-20.

28. Ribeiro GHFP, Kerr LM, Haikel RL, Peres SV, Matthes AGZ, Depieri Michelli RA, et al. Modified radical mastectomy: A pilot clinical trial comparing the use of conventional electric scalpel and harmonic 
scalpel. Int J Surg. 2013;11(6):496-500.

29. Kontos M, Kothari A, Hamed H. Effect of ultrasonic shear on seroma formation following surgery for breast cancer: A prospective randomized study. J BUON. 2008;13(2):223-30.

30. Mancaux A, Naepels P, Mychaluk J, Abboud P, Merviel P, Fauvet R. Prevention of seroma postmastectomy by surgical padding technique. Gynecol Obstet Fertil. 2015;43(1):13-7.

\section{Tables}

Table 1: Preoperative data of the studied groups. 


\begin{tabular}{|c|c|c|c|}
\hline Variables & HF Group $(n=49)$ & CE Group $(n=50)$ & $P$ value \\
\hline Age (mean $\pm S D)$ & $49.51 \pm 11.3$ & $48.1 \pm 11.1$ & 0.53 \\
\hline \multicolumn{4}{|l|}{ Years } \\
\hline Females (No, \%) & $48(98 \%)$ & $48(96 \%)$ & 0.51 \\
\hline$B M I($ mean $\pm S D)$ & $30.65 \pm 5.4$ & $31 \pm 6.5$ & 0.78 \\
\hline \multicolumn{4}{|l|}{$\mathrm{Kg} / \mathrm{m}^{2}$} \\
\hline Smoking (No, \%) & $7(14.3 \%)$ & $7(14 \%)$ & 0.96 \\
\hline Family history (No, \%) & $2(4.1 \%)$ & $2(\%)$ & 0.98 \\
\hline$D M($ No, \%) & $13(26.5 \%)$ & $12(14 \%)$ & 0.77 \\
\hline $\operatorname{HTN}(\mathrm{No}, \%)$ & $13(26.5 \%)$ & $12(14 \%)$ & 0.77 \\
\hline Others No, (\%) & $15(30.6 \%)$ & $21(42 \%)$ & 0.24 \\
\hline \multicolumn{4}{|l|}{ Histological Type (No, \%) } \\
\hline - Invasive duct carcinoma & $41(83.7 \%)$ & $42(84 \%)$ & \\
\hline DCIS & $4(8.2 \%)$ & $7(14 \%)$ & 0.32 \\
\hline - Invasive lobular carcinoma & $1(2 \%)$ & 0 & \\
\hline - Invasive micropapillary carcinoma & $2(4.1 \%)$ & 0 & \\
\hline Lobular Carcinoma. & $1(2 \%)$ & 0 & \\
\hline - Medullary breast cancer & 0 & $1(2 \%)$ & \\
\hline \multicolumn{4}{|l|}{ Receptors status (No, \%) } \\
\hline \multirow{2}{*}{$\begin{array}{l}\text { ER positive } \\
\text { PR positive }\end{array}$} & $\begin{array}{l}32(65.3 \%) \\
30(61.2 \%)\end{array}$ & $\begin{array}{l}37(74 \%) \\
31(62 \%)\end{array}$ & $\begin{array}{l}0.21 \\
0.32 \\
0.33\end{array}$ \\
\hline & $18(36.7 \%)$ & $20(40 \%)$ & \\
\hline \multicolumn{4}{|l|}{ Her2 positive } \\
\hline Pre-CTH tumor size (mean \pm SD) & $3.3 \pm 0.6$ & $3.2 \pm 0.57$ & 0.39 \\
\hline \multicolumn{4}{|l|}{ Years } \\
\hline \multirow{2}{*}{$\begin{array}{l}\text { Post-CTH tumor size (mean } \pm S D) \\
\text { Years }\end{array}$} & $1.6 \pm 0.6$ & $1.5 \pm 0.58$ & 0.13 \\
\hline & & & \\
\hline \multicolumn{4}{|l|}{ Clinical Nodes (No, \%) } \\
\hline $0 \quad 0$ & $17(34.7 \%)$ & $31(62 \%)$ & 0.023 \\
\hline 1 & $15(30.6 \%)$ & $10(20 \%)$ & \\
\hline
\end{tabular}




\begin{tabular}{|c|c|c|c|c|}
\hline \multirow{2}{*}{\multicolumn{2}{|c|}{$\begin{array}{c}2 \\
\text { TNM stage }\end{array}$}} & \multirow[t]{2}{*}{$17(34.7 \%)$} & \multicolumn{2}{|l|}{$9(18 \%)$} \\
\hline & & & & \\
\hline • & $I$ & $3(6.1 \%)$ & $3(6 \%)$ & 0.15 \\
\hline ○ & II & $22(44.9 \%)$ & \multicolumn{2}{|c|}{$28(56 \%)$} \\
\hline 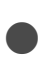 & III & $29(59.1 \%)$ & \multicolumn{2}{|l|}{$19(38 \%)$} \\
\hline \multicolumn{2}{|c|}{ Type of CTH } & \multirow{3}{*}{$\begin{array}{l}6(12.3 \%) \\
43(87.7 \%)\end{array}$} & \multirow{3}{*}{$\begin{array}{l}13(26 \%) \\
37(74 \%)\end{array}$} & \multirow[t]{3}{*}{0.17} \\
\hline ○ & $A C+T T$ & & & \\
\hline ○ & $A C+T$ & & & \\
\hline \multicolumn{2}{|c|}{ No. of Cycles } & \multirow{4}{*}{$\begin{array}{l}1(2 \%) \\
48(98 \%) \\
0\end{array}$} & \multirow{4}{*}{$\begin{array}{l}1(2 \%) \\
2(4 \%) \\
47(94 \%)\end{array}$} & \multirow[t]{4}{*}{0.5} \\
\hline 0 & 4 cycles & & & \\
\hline • & 6 cycles & & & \\
\hline 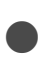 & 8 cycles & & & \\
\hline \multicolumn{5}{|c|}{ Radiological Response } \\
\hline 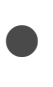 & $C R$ & \multirow{4}{*}{$\begin{array}{l}5(10.2 \%) \\
2(4.1 \%) \\
4(8.2 \%) \\
38(77.6 \%)\end{array}$} & \multirow{4}{*}{$\begin{array}{l}5(10 \%) \\
4(8 \%) \\
2(4 \%) \\
39(78 \%)\end{array}$} & \multirow[t]{4}{*}{0.72} \\
\hline • & $D P$ & & & \\
\hline 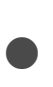 & $S D$ & & & \\
\hline ○ & $P R$ & & & \\
\hline
\end{tabular}

BMI: Body mass index; CTH: Chemotherapy; DM: Diabetes mellitus; HTN: Hypertension.

Table 2: Intraoperative data of the included patients 


\begin{tabular}{|c|c|c|c|}
\hline Variables & HF Group $(n=49)$ & CE Group $(n=50)$ & $P$ value \\
\hline $\begin{array}{l}\text { Duration of operation } \\
\text { (mean } \pm S D \text { ) minutes }\end{array}$ & $101.32 \pm 27.3$ & $139.3 \pm 31.9$ & 0.001 \\
\hline $\begin{array}{l}\text { Blood loss } \\
\text { (mean } \pm \text { SD) } m L\end{array}$ & $117.14 \pm 35.6$ & $187 \pm 49.8$ & 0.001 \\
\hline $\begin{array}{l}\text { No, of total lymph node } \\
\text { (mean } \pm \text { SD) }\end{array}$ & $18.24 \pm 4.7$ & $17.46 \pm 5.9$ & 0.46 \\
\hline $\begin{array}{l}\text { No, of positive lymph node } \\
\text { (mean } \pm S D \text { ) }\end{array}$ & $3.2 \pm 4.4$ & $2.8 \pm 4.7$ & 0.69 \\
\hline \multicolumn{4}{|l|}{ pTNM (No, \%) } \\
\hline - 1 & $29(59.2 \%)$ & $39(78 \%)$ & \\
\hline - II & $6(12.2 \%)$ & $5(10 \%)$ & \\
\hline - III & $14(28.6 \%)$ & $6(12 \%)$ & 0.168 \\
\hline
\end{tabular}

pTNM: pathological TNM

Table 3: Postoperative data of the included patients 


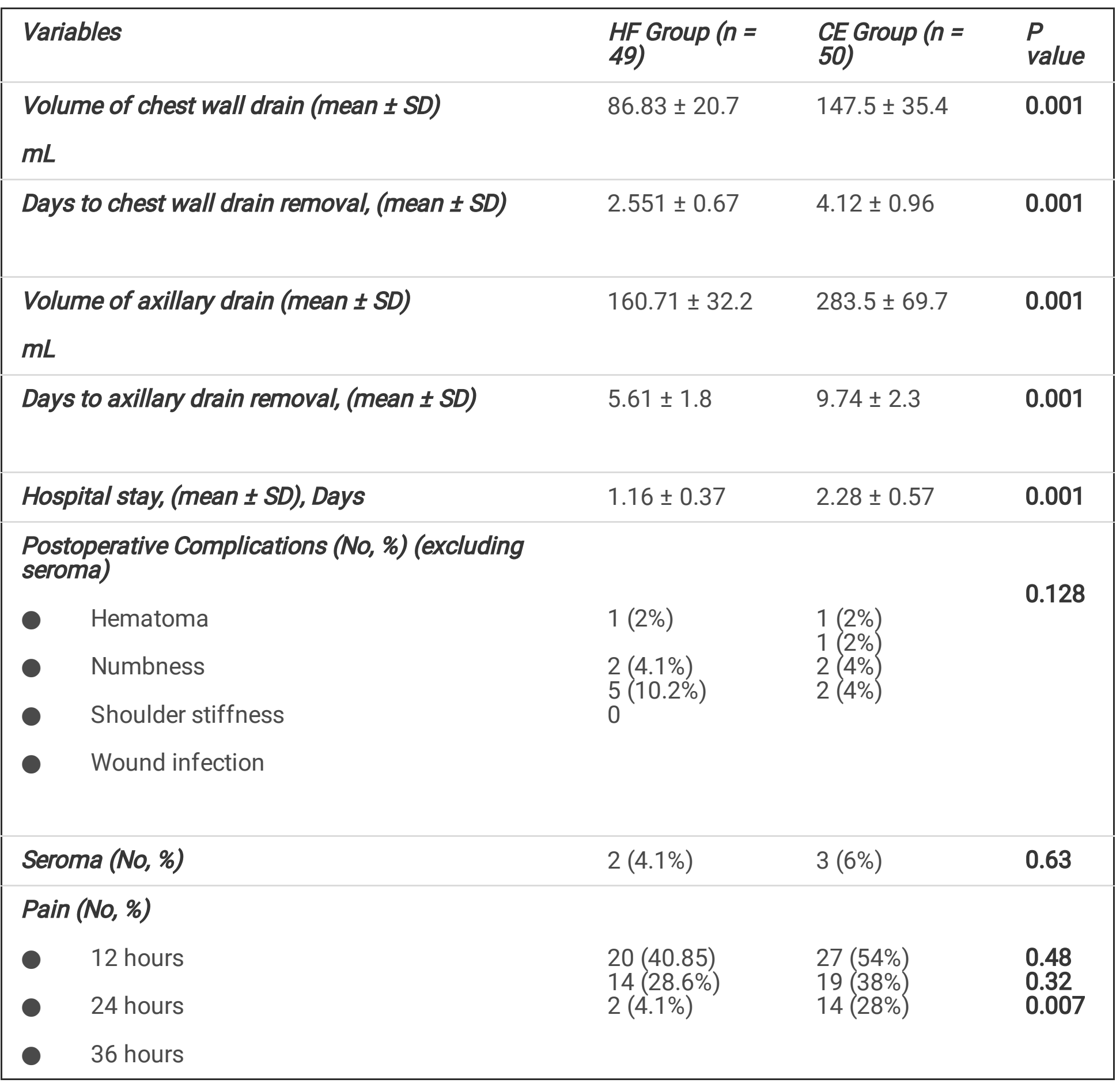

Table 4: Comparison of patients with and without seroma 


\begin{tabular}{|c|c|c|c|}
\hline Variables & Seroma $(n=5)$ & No Seroma $(n=94)$ & $P$ value \\
\hline Age $($ mean $\pm S D)$ & $51.6 \pm 6.5$ & $48.6 \pm 11.4$ & 0.56 \\
\hline \multicolumn{4}{|l|}{ Years } \\
\hline Females (No, \%) & $5(100 \%)$ & 91 (96.8\%) & 0.89 \\
\hline$B M I($ mean $\pm S D)$ & $30.8 \pm 6.1$ & $31.2 \pm 5.2$ & 0.89 \\
\hline \multicolumn{4}{|l|}{$\mathrm{Kg} / \mathrm{m}^{2}$} \\
\hline Smoking (No, \%) & 0 & $14(14.9 \%)$ & 0.35 \\
\hline Family history (No, \%) & $1(20 \%)$ & $3(3.2 \%)$ & 0.07 \\
\hline$D M($ No, \%) & $1(20 \%)$ & $24(25.5 \%)$ & 0.78 \\
\hline HTN (No, \%) & $2(40 \%)$ & $23(24.5 \%)$ & 0.43 \\
\hline \multicolumn{4}{|l|}{ Receptors status (No, \%) } \\
\hline Her2 positive & $4(80 \%)$ & $34(36.1 \%)$ & 0.001 \\
\hline \multicolumn{4}{|l|}{ TNM stage } \\
\hline \multirow{3}{*}{$\begin{array}{ll}\bullet & I \\
\bullet & I I \\
\cdot & I I I\end{array}$} & 1 & 5 & \\
\hline & 1 & 32 & 0.018 \\
\hline & 3 & 57 & \\
\hline \multicolumn{4}{|l|}{ Type of CTH } \\
\hline - $\quad A C+T T$ & $\begin{array}{l}2(20 \%) \\
3(60 \%)\end{array}$ & $\begin{array}{l}17(18.1 \%) \\
77(81.9 \%)\end{array}$ & 0.42 \\
\hline$\quad A C+T$ & & & \\
\hline \multicolumn{4}{|l|}{ No. of Cycles } \\
\hline - 4 cycles & & $\begin{array}{l}1(1.1 \%) \\
3(3.3 \%)\end{array}$ & 0.49 \\
\hline - 6 cycles & $5(100 \%)$ & & \\
\hline 8 cycles & & & \\
\hline \multicolumn{4}{|l|}{ Radiological Response } \\
\hline - $\quad C R$ & 0 & 27 & \\
\hline - $D P$ & 2 & 22 & 0.43 \\
\hline$\quad S D$ & 2 & 24 & \\
\hline - $\quad P R$ & 1 & 21 & \\
\hline
\end{tabular}




\begin{tabular}{|c|c|c|c|}
\hline $\begin{array}{l}\text { Pre-CTH tumor size (mean } \pm S D) \\
\text { Years }\end{array}$ & $3.4 \pm 0.9$ & $3.2 \pm 0.59$ & 0.58 \\
\hline $\begin{array}{l}\text { Post-CTH tumor size (mean } \pm S D) \\
\text { Years }\end{array}$ & $2 \pm 0.7$ & $1.6 \pm 0.6$ & 0.17 \\
\hline $\begin{array}{l}\text { Duration of operation } \\
\text { (mean } \pm S D \text { ) minutes }\end{array}$ & $101 \pm 28.9$ & $121.5 \pm 35.3$ & 0.21 \\
\hline $\begin{array}{l}\text { Blood loss } \\
(\text { mean } \pm S D) m L\end{array}$ & $180 \pm 39.1$ & $150.9 \pm 56.1$ & 0.25 \\
\hline $\begin{array}{l}\text { No, of total lymph node } \\
\text { (mean } \pm \text { SD) }\end{array}$ & $16.4 \pm 4.9$ & $17.9 \pm 5.3$ & 0.53 \\
\hline $\begin{array}{l}\text { Volume of chest wall drain (mean } \pm S D \text { ) } \\
m L\end{array}$ & $90 \pm 28.2$ & $118.9 \pm 42.2$ & 0.13 \\
\hline Days to chest wall drain removal, (mean $\pm S D)$ & $2.551 \pm 0.67$ & $4.12 \pm 0.96$ & 0.046 \\
\hline $\begin{array}{l}\text { Volume of axillary drain (mean } \pm S D \text { ) } \\
m L\end{array}$ & $192 \pm 62.2$ & $224.3 \pm 83$ & 0.39 \\
\hline Days to axillary drain removal, (mean $\pm S D$ ) & $7.4 \pm 1.5$ & $7.7 \pm 2.9$ & 0.81 \\
\hline Hospital stay, (mean \pm SD), Days & $1.8 \pm 0.8$ & $1.73 \pm 0.7$ & 0.82 \\
\hline
\end{tabular}

BMI: Body mass index; CTH: Chemotherapy; DM: Diabetes mellitus; HTN: Hypertension.

Table 5: Multiple logistic regression of predictors of postoperative complications 


\begin{tabular}{|c|c|c|c|c|c|c|}
\hline \multirow[t]{2}{*}{ Variables } & \multicolumn{3}{|c|}{$\begin{array}{l}\text { Postoperative complications } \\
\text { (excluding seroma) }\end{array}$} & \multicolumn{3}{|c|}{ Seroma } \\
\hline & $O R$ & $95 \% \mathrm{Cl}$ & $P$ value & $O R$ & $95 \% \mathrm{Cl}$ & $\begin{array}{l}P \\
\text { value }\end{array}$ \\
\hline Her-2Positive & 1.338 & $(0.31-5.6)$ & 0.69 & 11.721 & $\begin{array}{l}(1.1- \\
128.6)\end{array}$ & 0.044 \\
\hline T4 stage & 0.177 & $(0.21-1.5)$ & 0.115 & 2.532 & $\begin{array}{l}(0.32- \\
19.8)\end{array}$ & 0.37 \\
\hline $\begin{array}{l}\text { Days to chest wall drain } \\
\text { removal > } 3 \text { days }\end{array}$ & 0.128 & $(0.015-1.1)$ & 0.06 & 0.272 & $\begin{array}{l}(0.027- \\
2.72)\end{array}$ & 0.26 \\
\hline
\end{tabular}

\section{Figures}

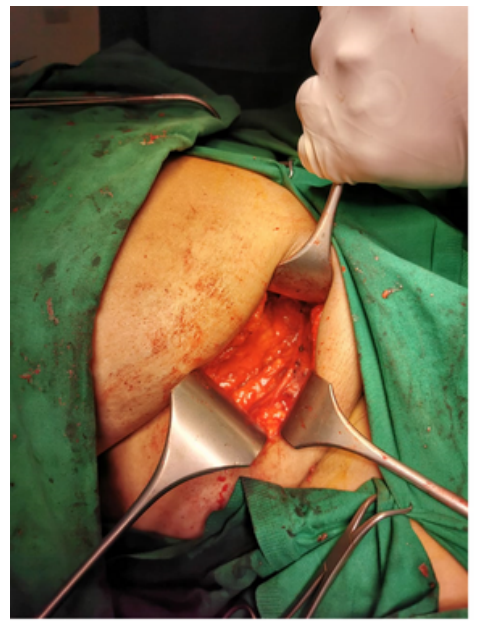

A

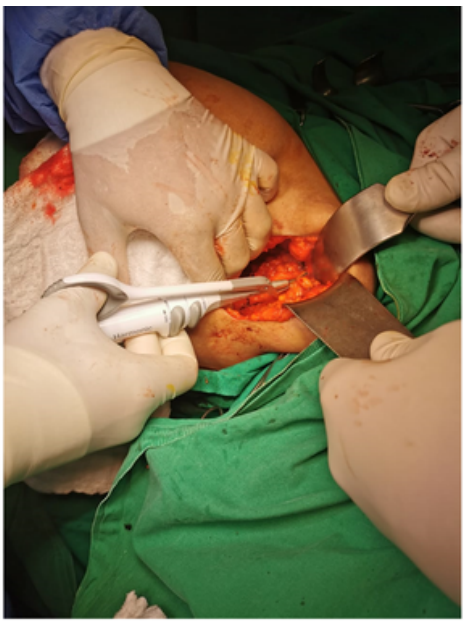

B

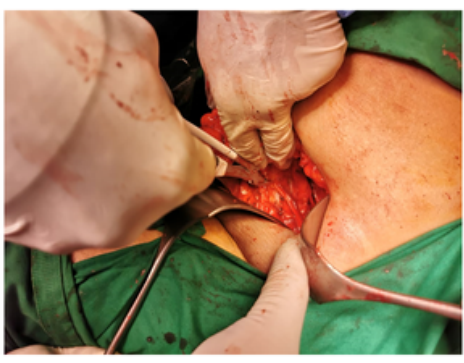

C

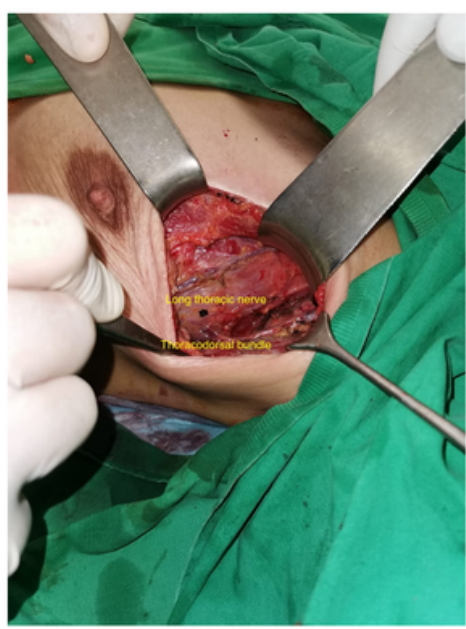

D

Figure 1

A: Dissection of breast tissue using harmonic scalpel. B. After wide local excision of Lt breast mass C. Dissection of axilla using harmonic scalpel D. Post axillary dissection with harmonic scalpel 